\title{
Educação ambiental: concepções de alunos de uma escola pública cidade de Barreiras no oeste da Bahia
}

Essa pesquisa foi feita em uma escola de ensino fundamental pública para buscar entender e classificar a percepção dos alunos sobre o meio ambiente. 0 ensino em educação ambiental, preconizado pela PCN's é uma política pública que busca melhorar o entendimento dos jovens estudantes sobre o meio ambiente. Esse entendimento deve ir além dos conceitos formais contidos em livros e interagir diretamente com a realidade vivenciada por cada aluno. Foi utilizado como metodologia, questionário de cinco perguntas abertas e confecção de ilustração sobre o que é o meio ambiente. Isso permitiu classificar a percepção dos alunos na sua maioria, $65 \%$ como uma romantizada, $9 \%$ reducionista, $10 \%$ abrangente e $16 \%$ sócio ambiental. 0 resultado deixa claro a falta de interdisciplinaridade do tema 'Meio Ambiente' nas escolas públicas e a necessidade urgente dessa inclusão para construção de indivíduos capazes de contribuir para um meio ambiente melhor e saudável.

Palavras-chave: Sustentabilidade; Meio ambiente; Barreiras; Escola.

\section{Environmental education: conceptions of students from a public school in the city of Barreiras in western Bahia, Brazil}

\begin{abstract}
This research was conducted in a public elementary school to understand and classify students' perceptions of the environment. Teaching in environmenta education, advocated by PCN's is a public policy that seeks to improve the understanding of young students about the environment. This understanding must go beyond the formal concepts contained in books and interact directly with the reality experienced by each student. It was used as methodology, questionnaire of five open questions and illustration of what is the environment. This allowed us to classify the perception of the majority of students, $65 \%$ as romanticized, $9 \%$ reductionist, $10 \%$ comprehensive and $16 \%$ social environmental. The result makes clear the lack of interdisciplinary of the theme 'Environment' in public schools and the urgent need for this inclusion to build individuals able to contribute to a better and healthy environment.
\end{abstract}

Keywords: Sustainability; Environment; Barreiras; School.

Topic: Desenvolvimento, Sustentabilidade e Meio Ambiente

Reviewed anonymously in the process of blind peer.

Ranieldo Barreiras Barbosa Souza (iD)

Universidade Federal do Oeste da Bahia, Brasil

http://lattes.cnpq.br/2995123274670779

http://orcid.org/0000-0001-6947-2872

ranieldosouza89@gmail.com

Antonio José da Silva Filho

Faculdade Educacional da Lapa, Brasil

http://lattes.cnpq.br/6120838153202195

http://orcid.org/0000-0003-0261-4164

antoniojsfilho85@gmail.com

Raniele Barbosa Souza

Universidade Estadual da Bahia, Brasil

http://lattes.cnpq.br/6088479168824696

http://orcid.org/0000-0002-6117-3752

ranielesbarbosa@gmail.com
Received: $\mathbf{2 1 / 1 1 / 2 0 1 9}$

Approved: 12/02/2020
Referencing this:

SOUZA, R. B. B.; SILVA FILHO, A. J.; SOUZA, R. B.. Educação ambiental: concepções de alunos de uma escola pública cidade de Barreiras no oeste da Bahia. Natural Resources, v.10, n.1, p.10-16, 2020. DOI: http://doi.org/10.6008/CBPC2237-9290.2020.001.0002 


\section{INTRODUÇÃO}

O ensino da Educação Ambiental, tem a finalidade exclusiva de desenvolver no indivíduo humano novas concepções que o fazem desenvolver atitudes de preservação do mundo em que vive como um todo. Essa compreensão se dá de maneira formal, durante todo o período escolar do indivíduo, e pode ser não formal, que se baseia da vivência em comunidade (MARANDINO et al., 2009) ou ainda da junção dos dois em um determinado espaço social (LEITE et al., 2001). Para Marins (2004), é por meio da reflexão sobre o espaço que ocupa no mundo que o ser humano desenvolve sua forma de agir sobre ele.

A educação ambiental nas escolas, tem sido uma forma de discutir a importância da conservação do meio ambiente e traz à baila, os desafios da contemporaneidade nesse processo de preservar, e engloba vários elementos, dentre eles o socioeconômico, cultural e político (FONTANA, 2002). Suavè (2005) relata que há dois tipos bem claros de definição de meio ambiente para o indivíduo. O que não se insere como parte do meio ambiente e a que se insere no meio ambiente, formando uma totalidade (vizinhança, moradia, escola, parque, florestas, animai, etc.) que precisa ser respeitada e preservada. Essa segunda definição, enquadra as discursões sobre o meio ambiente como uma questão também social (RIGOTA, 2002).

O debate em sala de aula e a reflexão do próprio indivíduo, são de extremas importâncias para a elaboração de pesquisas acerca da visão do indivíduo no mundo. E se torna um instrumento para, depois dessa percepção, o educador desenvolver didáticas de inserção desse tema no dia a dia dos alunos. Essa inserção de acordo com Leff (2005) deve ser livre de conceitos já formados, trazendo para vida dos educandos temáticas ecológicas que os façam se relacionar com o meio e desenvolver valores, adquirindo nova mentalidade e conhecimento nas várias matérias que compõem a ementa.

De acordo com Meyer (1991), antes de qualquer abordagem, é necessário que o educador, sem imposição, entenda a visão que cada um tem do meio que está inserido. Para Guimarães (2002), educar não é tornar o aluno ambientalista apenas por valores estritamente verdes. É levar o estudante a uma percepção crítica do mundo, da sociedade, levando-o a pensar por si só e a questionar com responsabilidade. Na Bahia, a Educação Ambiental está incorporada às redes escolares públicas particulares. A sociedade dentro e fora do ambiente escolar já visualizam ações desenvolvidas que outrora não existiam. Mas a maioria dessas ações ainda ocorrem de forma rotulada, programada, sem causar a reflexão do indivíduo sobre o seu papel, sendo pouco eficaz para a produção de resoluções aos desafios ambientais da atualidade (GUIMARÃES, 2002).

Essa pesquisa se justifica na urgência da Educação Ambiental ser acrescida ao processo educacional, às recentes discussões sobre as questões ambientais, e as transformações de novo saber, diante de uma realidade ambiental atual (GUIMARÃES, 2002). Com isso, esse estudo de caso tem por objetivo investigar as reflexões sobre o meio ambiente de estudantes de uma escola de ensino médio da rede estadual, trazendo a possibilidade de auxiliar o educador na percepção de cada indivíduo, e a partir disso, possibilitar novas ferramentas de trabalho em sala de aula. 


\section{MATERIAIS E MÉTODOS}

\section{Local de estudo}

Conhecida como Território de Identidade da Bacia do Rio Grande, a cidade de Barreiras está localizada na Região Oeste do Estado da Bahia e possui uma população estimada de 153.831 mil habitantes conforme último censo realizado pelo IBGE em 2016. Sua área municipal tem aproximadamente $7.859 \mathrm{Km}^{2}$ e se distancia por cerca de 900 km da capital do Estado da Bahia, Salvador e cerca de 622 km da capital política do Brasil, Distrito Federal - Brasília. Seus limites territoriais compreendem o município de Riacho das Neves ao Norte, São Desidério ao Sul, Angical e Catolândia ao leste e Luís Eduardo Magalhães ao Oeste. Barreiras também tem divisa com três outros estados do país, sendo eles Goiás, Tocantins e Piauí, o que coloca o munícipio em rota de destaque como a principal cidade do Oeste da Bahia.

A região é coberta pela vegetação Cerrado e o clima predominante é o tropical, com temperatura média anual de $24,9^{\circ} \mathrm{C}$. A cidade é bastante povoada e sua formação geográfica é composta por 47 bairros. A gestão municipal é responsável exclusivamente pela educação fundamental. As escolas municipais estão distribuídas pelos bairros da sede do município e atendeu, nesse ano de 2019, cerca de 23 mil alunos distribuídos entre ensino infantil e ensino fundamental com uma estrutura que abrange 32 escolas, com previsão de ampliação desse número até início do ano letivo de 2020 com novas construções em andamento (SME, 2019).

Dados da Secretaria Municipal de Educação (2015), os educandos contam com um quadro de cerca de dois mil profissionais diretos e na ativa, sendo que cerca de 93\% desses, estão atuantes no ensino fundamental e cerca de $7 \%$ no ensino infantil. O trabalho foi desenvolvido numa Escola Pública Municipal, localizado na região central da cidade de Barreiras, no período de 05 de Junho de 2019. Esse período compreende a Semana Nacional do Meio Ambiente e é acompanhado de eventos educativos (palestras, debates, etc.) voltados para o Meio Ambiente em todas as escolas da rede pública, Municipal e Estadual. Participaram dessa pesquisa 90 alunos distribuídos entre 8음 ano e 9으 ano (ensino fundamental).

Após a apresentação dos pesquisadores e o objetivo da pesquisa e, sendo solicitado que o professor se retirasse da sala de aula (para que não houvesse influência sobre as respostas dos alunos) foi aplicado em primeiro momento um questionário com cinco perguntas qualitativas e quantitativas acerca do Meio Ambiente (PARASURAMAN, 1991). Esse questionário foi entregue a cada aluno em cada sala simultaneamente nas três turmas.

Os alunos tiveram 40 minutos para responder o questionário. Foram instruídos a ser o mais objetivo possível nas respostas. Os alunos não foram instruídos a se identificarem no questionário. As perguntas aplicadas foram: O que é o meio Ambiente?; O que é Educação Ambiental para você?; Você acha que o homem depende da natureza pra sobreviver? Justifique sua resposta?; Para você, quais as ações do homem que prejudicam a natureza?; Você estuda sobre o meio ambiente na sua escola o ano todo? Em quais disciplinas?.

Após o tempo de resposta, os questionários foram recolhidos e colocados em envelopes e procedeu- 
se com a segunda atividade. Nesse segundo momento, foi distribuído papel em branco (folha A4) para os alunos e estojo lápis de cor de doze cores e se pediu que eles, utilizando formas e/ou figuras, mostrasse qual a sua visão de Meio Ambiente. Essa atividade foi desenvolvida nas três turmas simultaneamente afim de que as respostas fossem as mais originais possíveis.

Os alunos tiveram o tempo estimado em 30 minutos para desenvolver essa atividade. Nessa atividade também não foram instruídos a se identificarem. Após isso, todo material foi colocado em um único envelope para a análise ser feita de maneira que não fosse possível identificar a sala aplicada. Em posse desses dados, foi feita a divisão de grupos, de acordo com as respostas, seguindo Tamaio (2000) e Fontana (2002), conforme a Tabela 1.

Tabela 1: Classificação de percepção do meio ambiente.

\begin{tabular}{|l|l|}
\hline Classificação & Definição \\
\hline Romântica & Mãe Natureza. Beleza e harmonia, sem a inserção do homem. \\
\hline Reducionista & Natureza = aspectos físicos (água, ar, rocha, etc.). O homem não faz parte do meio. \\
\hline Abrangente & Natureza = aspectos naturais + resultado da atividade humana. \\
\hline Socio Ambiental & Homem faz parte da natureza, homem destrói o seu próprio meio. \\
\hline
\end{tabular}

\section{RESULTADOS E DISCUSSÃO}

Na totalidade dos 90 Questionários distribuídos, 57\% dos alunos disseram que o meio ambiente é resumido somente à fauna e a flora. $15 \%$, como o meio que necessita ser preservado, $9 \%$ como o lugar que vivemos e 19\% disseram que o meio ambiente é o lugar onde o homem destrói. Venturieri et al. (2016), apresentaram resultados semelhantes, seguindo o mesmo raciocínio de definições. Isso talvez seja fruto de uma grade curricular presente nas escolas que não está acompanhando a atual realidade ambiental, dando ênfase apenas a conceito pré-formulados. Em uma outra observação, nota-se que essas respostas corroboram com o publicado pelo Ministério do Meio ambiente (CRESPO, 1998), onde a tendência é o indivíduo não se colocar como parte do meio ambiente.

Sobre o conceito de Educação ambiental, 70\% apontaram como ensinar a preservar o meio ambiente. $22 \%$ disseram que é manter o ambiente livre de sujeiras, queimadas e desmatamento e $8 \%$ disseram que é aprender a respeitar a natureza. Nota-se que há um entendimento maior sobre aprender o cuidar da natureza que na pesquisa de Venturieri et al. (2016) e seguindo de um gradativo entendimento quanto ao respeito pelo ambiente e sobre sua limpeza e alterações (queimadas e desmatamentos).

Quando questionados sobre se o homem depende da natureza para sobreviver, 90\% responderam que sim. Como justificativa, cada um disse sobre a importância de se preservar e respeitá-lo. 10\% disseram que o homem não depende da natureza, justificando que o mesmo só destrói. Houve um aumento da percepção da dependência do homem em relação ao meio ambiente, se comparado com os resultados de Venturieri et al. (2016). Isso acontece provavelmente, por conta dos alertas noticiados nesses últimos anos, com relação às grandes queimadas, desmatamentos da Amazônia, emissão de gazes, acompanhados de protestos sociais e políticos. Um indício de que a educação informal (meio, TV, internet) está também fazendo um papel positivo para a aquisição dessa percepção, já que a ementa curricular não abrange tais situações atuais. Em seu estudo com alunos, Brondani et al. (2010), há uma conscientização sobre a relação 
estrita entre o meio e o homem, onde um afeta diretamente o outro, positiva ou negativamente. A escola deve apresentar propostas pedagógicas voltadas ao ensino de educação ambiental para levar o aluno a trilhar por outros caminhos do conhecimento e mudar, assim suas ações Reigota (1998).

Quando indagados sobre quais os danos que o homem causa a natureza, $30 \%$ falaram sobre desmatamento. $18 \%$ sobre poluição dos rios, $17 \%$ apontaram a extinção de animais e $35 \%$ disseram que eram lixos nas ruas e fumaças de carro. Esse resultado mostra claramente que os alunos são capazes de perceber a ação direta do homem no meio ambiente. Conseguem claramente ver essas alterações dentro e fora da cidade. Estão conscientes dos desafios de cada município, talvez dos bairros onde vivem que pela infraestrutura, fragilizada conseguem perceber a poluição de perto. Godoy et al. (2008) teve essa mesma percepção em um trabalho semelhante desenvolvido com alunos.

Questionados sobre se a temática 'Meio Ambiente' já foi trabalhada em sala de aula ao longo do período letivo, $71 \%$ disseram que sim. $29 \%$ disseram que não. Dos que disseram que sim, todos (100\%) disseram terem visto somente na disciplina de ciências. Venturieri et al. (2016), teve um resultado parecido com relação à falta interdisciplinaridade do tema.

Essa falha se dá talvez à falta de preparo pedagógico e de preparação dos professores para a abordagem do tema nas diversas disciplinas ofertadas para o ensino fundamental. A interdisciplinaridade é preconizada pelos Parâmetros Curriculares Nacionais (PCN's) desde o ano de 1997 (BRASIL, 1997). Tudo sugere que há uma evolução lenta da aplicabilidade interdisciplinar do tema nas escolas.

\section{Classificações}

Quanto às ilustrações e o comportamento das respostas, 65\% apresentaram uma ilustração Romântica da natureza. Suas belezas naturais no todo, mãe, rainha, sem o toque do homem. Levando a percepção de que sem o homem, a natureza é algo intocável (TAMAIO, 2000). Houve uma prevalência de árvores, animais, flores, aves e um realce da cor verde. Resultado semelhante aos apresentados por Venturieri et al. (2016).

Um total de $9 \%$ das ilustrações e respostas foram classificadas como reducionista com destaques de floresta. Árvores de grande porte, sem a presença do homem. Aproximaram-se dos números obtidos por Hoeffel et al. (2004) e Venturieri et al. (2016). Como classificação Abrangente, 10\% apresentaram uma realidade de inserção geral dentro do meio. Ruas, casas, homem, florestas, rios, tudo juntos em harmonização. Número próximo do apresentado por Venturieri et al. (2016).

Por fim, 16\% das ilustrações apresentaram uma classificação Sócio Ambiental. Esses mostraram claramente a presença de lixos, desmatamentos, queimadas e esgotos em seus desenhos, deixando perceptível a influência direta no homem na transformação do meio ambiente. Um número bem maior que o de Venturieri et al. (2016), que foi de 6\%. Isso evidencia o aumento da percepção dos alunos com relação às alterações a sua volta. Essa percepção é positiva no processo ensino-aprendizagem. Essa classificação fica mais clara no gráfico a Gráfico 1. 


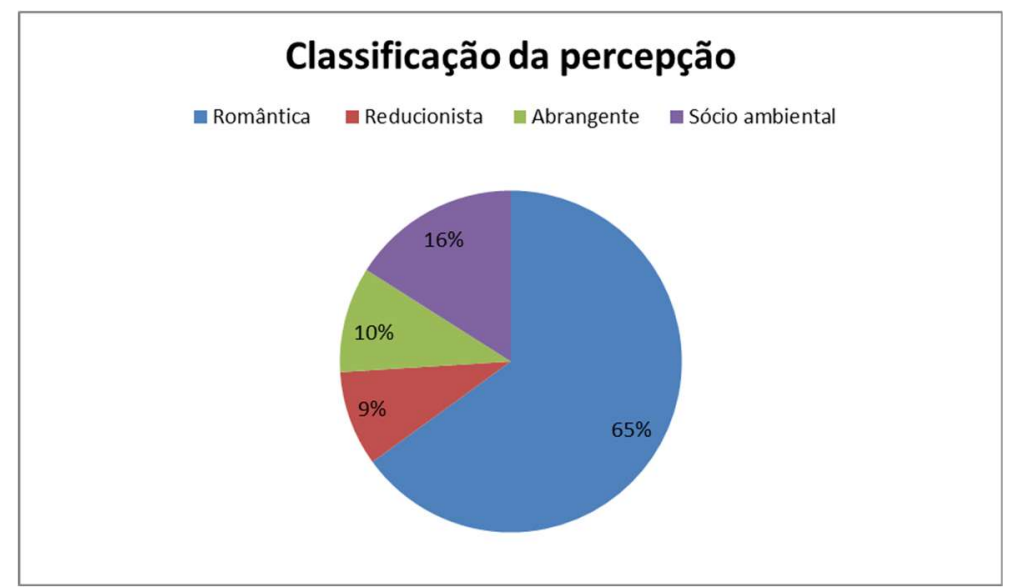

Gráfico 1: Classificação da percepção ambiental dos alunos com base em suas ilustrações.

\section{CONCLUSÕES}

Há uma percepção por parte dos alunos de que o homem não compõe o meio ambiente. Os que entendem que o homem faz parte, e por uma minoria, também entendem que o homem acaba com o meio do qual faz parte. A forma errada com a qual o meio ambiente está sendo abordado em mídias e escola, faz com que os alunos reduzem a natureza apenas a água, pedra, animais e plantas.

Há uma romantização da percepção ambiental dos alunos, o que confirma essa percepção dela sem a presença do homem. Essa romantização, segue tendências de influências das mídias (TAMAIO, 2000), que apresentam a natureza como perfeita, deixando a crise que a afeta apenas para os telejornais, poucos acessados pelos jovens.

A escola estudada não segue o determinado pelo PCN's quando não há a interdisciplinaridade da temática, reduzindo apenas a uma matéria específica, não havendo assim um trabalho constante com os alunos. A escola deve inserir em seu plano curricular visando guiar o aluno pelas trilhas da preservação e deixá-los cada vez mais próximos das realidades ambientais existentes (FREIRE, 2003).

\section{REFERÊNCIAS}

BRASIL. Secretaria de Educação Fundamental. Parâmetros Curriculares Nacionais. Brasília: MEC, 1997.

BRONDANI, C. J.; HENZEL, M. E.. Análise sobre a conscientização ambiental em escolas da rede municipal de ensino. Revista Brasileira de Educação Ambiental, v.5, n.1, p.37-44, 2010.

CRESPO, S.. O que o brasileiro pensa do meio ambiente, do desenvolvimento e da sustentabilidade. Rio de Janeiro: MAST, 1998.

FONTANA, K. B.. A concepção de meio ambiente de alunos do curso de pedagogia a distância e a importância da mediação tecnológica: dificuldades e perspectivas. 2002.

FREIRE, P.. Pedagogia do oprimido. 36 ed. Rio de Janeiro: Paz e Terra, 2003.

GODOY, C. E. C.; SANTOS, C. G. B.; CORREIA, P. R. M.. A aprendizagem baseada em problemas e a introdução de conceitos químicos nas aulas de ciências no ensino fundamental II. In: ENCONTRO NACIONAL DE ENSINO DE QUÍMICA, 14. Anais. Curitiba: UFPR, 2008.

GUIMARÃES, M.. Diagnóstico da percepção socioambiental de Professores em Xerém (D. Caxias/RJ) e as relações com o processo de modernização. In: ENCONTRO DA ASSOCIAÇÃO NACIONAL DE PÓS GRADUAÇÃO E PESQUISA EM AMBIENTE E SOCIEDADE. Anais. Indaiatuba: ANPPAS, 2002.

HOEFFEL, J. L.. Concepções e percepções da natureza na Área de Proteção Ambiental do Sistema Cantareira. In: CONGRESSO BRASILEIRO DE UNIDADES DE CONSERVAÇÃO, 4. Anais. Curitiba: Fundação $O$ Boticário de Proteção à Natureza, 2004. p.346-356.

LEFF, E.. Saber ambiental: Sustentabilidade, Racionalidade, Complexidade, Poder. Petrópolis: Vozes, 2005.

MARANDINO, M.; SELLES, S. E.; FERREIRA, M. S.. Ensino de Biologia: histórias e práticas em diferentes espaços educativos. São Paulo: Cortez, 2009. 
MARINS, A.. Propostas de Atividades integradas no Ensino Fundamental. In: KINDEL, E. A. I.; SILVA, F. W.; SAMMARCO, Y. M.. Educação Ambiental: vários olhares e várias práticas. Porto Alegre: Mediação, 2004. p.79-84. 238

MEYER, M. A. A.. Educação Ambiental: uma proposta pedagógica. Em Aberto, v.10, n.49, p.41-46, 1991.

LEITE, A. L. T. A.; MININNI-MEDINA, N.. Educação ambiental: curso básico à distância: educação e educação ambiental. 2 ed. Brasília: MMA, 2001

PARASURAMAN, A.. Marketing research. 2 ed. Boston: Addison Wesley Publishing Company, 1991.

REIGOTA, M.. Desafios à Educação Ambiental escolar. In: CASCINO, F.; OLIVEIRA, J. F.; JACOBI, P.. Educação, meio ambiente e cidadania: reflexões e experiências. São Paulo:
SMA, 1998. p.27-32

SAUVÉ, L.. Educação Ambiental e desenvolvimento sustentável: uma análise complexa. Revista do Programa de Pós-graduação em Educação da UFMT, Cuia. Addison Wesley Publishing Company, bá, v.6, n.10, 1997.

TAMAIO, I.. A Mediação do Professor na Construção do Conceito de Natureza: Uma experiência de Educação Ambiental na Serra da Cantareira e Favela do Flamengo, São Paulo/SP. Dissertação (Mestrado em Educação) Universidade Estadual de Campinas, Campinas, 2000.

VENTURIERI, B.; SANTANA, A.. Concepções sobre meio ambiente de alunos do ensino fundamental em Belém-PA estudo de caso com a E.E.E.F.M. PROF. GOMES MOREIRA. Revbea, São Paulo, v.11, p.234-245, 2016.

A CBPC - Companhia Brasileira de Produção Científica (CNPJ: 11.221.422/0001-03) detém os direitos materiais desta publicação. Os direitos referem-se à publicação do trabalho em qualquer parte do mundo, incluindo os direitos às renovações, expansões e disseminações da contribuição, bem como outros direitos subsidiários. Todos os trabalhos publicados eletronicamente poderão posteriormente ser publicados em coletâneas impressas sob coordenação da Sustenere Publishing, da Companhia Brasileira de Produção Científica e seus parceiros autorizados. Os (as) autores (as) preservam os direitos autorais, mas não têm permissão para a publicação da contribuição em outro meio, impresso ou digital, em português ou em tradução. 